\title{
Ergonomic design intervention strategy for work tools development for women agro based workers in Northeast India
}

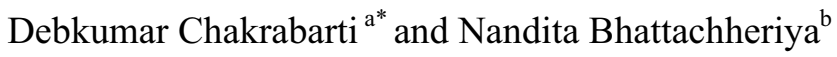 \\ ${ }^{a}$ Department of Design, Indian Institute of Technology Guwahati, Assam, India \\ ${ }^{b}$ Associate Professor, Assam Agricultural University, Jorhat, Assam, India
}

\begin{abstract}
Strategy for finding the appropriate strategy for work tool development has become a crucial issue in occupational wellness of varied nature of women workforce of Northeast India. This paper deals with ergonomics intervention through sustainable work tool design development process. Workers who frequently shift to different activities quite often in unorganised small-scale fruit processing units where productivity is directly related to the harvesting season require different work tools relevant to specific tasks and mostly workers themselves manage work tools of their own with available local resources. Whereas in contrast the tea-leaf pluckers are engaged in a single task throughout the year, and the work schedule and work equipment is decided and supplied to them based on the corporate decision where the workers do not have any individual control. Observations confirm the need for organising participatory workshops specific to trade based occupational well-being and different work tools for different tasks in mostly private owned unorganised sector. Implementation of single variety work tool development that supports a crucial component in tea-leaf plucking for which they are engaged in full time employment; and through a corporate decision a single design with its number of users makes a good effect.
\end{abstract}

Keywords: women agro based workers, Northeast India, ergonomics design strategy, sustainability

\section{Introduction}

Ergonomic design intervention is a process towards attaining optimal relationship between people and their work environment of the product and success. The approach has to be context specific, and the design may be a product, a system or a method of specialised working. Most of the women workforce of the northeast region of India are engaged in a range of occupations from traditional weaving and craft sector to upcoming fruit processing etc., various local agro-based mostly private small scale units as well as being engaged in tea leaf plucking in corporate sector of tea industries. This paper deals with sustainable work tool design development strategies suitable for this region specific to women workers.
In India ergonomics has gradually being incorporated into specific programmmes, like traditional agricultural development and industrial applications focusing on application of modern technology and forms of work organisation [1,2]. Many of the ergonomics studies on women workers in India have been carried out in the field of agriculture, beedi industry, handloom industry, tea industry, fish processing, and construction workers (HWWE proceedings series, conferences conducted by Indian Society of Ergonomics). Application of ergonomics in traditional village technology, work tools and work methods that go along with the existing skills and know-how knowledge continues to be the component of highest priority since the beginning of ergonomics activities in India [1, 2, 6-8].

\footnotetext{
* Corresponding author. E-mail: dc@iitg.ernet.in
} 
Low levels of productivity are the results of inadvertent neglect of ergonomic aspects in the design of equipment [3]. The effective design application in agro-based involvement is commendable with the reference parameters to evaluate the design development process for improving productivity along with their overall wellbeing.

It is still an emerging area with heterogeneous nature of research and practices in different spheres of technological needs, and the northeast India remains unnoticed. Vast population in this region with varied traditional occupations that supports the livelihood of locals and having export benefits remains unexplored. In a state like Assam, the large work force employed in agro-based industries and many other occupations comprises of majority of women. Specific to rural areas, family economic condition has compelled women to take up jobs which are low paying and they work for long hours without any much benefit. With the advantage of employing women in small scale industrial tasks, as they can do better repetitive tasks and less vocal in their demands, the consequences are low average earnings and high poverty risk. This specifically raises a need to set up a minimum wage level for tea estates [11].

Calcutta University, Department of Physiology, carried out a number of academic projects as master theses in Eastern India and conducted first ergonomic study in Assam Tea garden in 1979 [9]. Local institutions in northeast India, e.g., Home Science College, Assam Agricultural University, ICAR unit and NERIST carried out some academic interest studies mostly in the field of agriculture and tea cultivation from time to time. The present enquiry was aimed at looking into the strategies for ergonomics intervention in different agro-based sectors of women engagement in this region of country. Among four thrust crops (orange, pineapple, ginger and cashew nuts) in northeastern agro-horticultural belt, pineapple has promising industrial feasibility in Assam. As it is shifting

\section{Feasibility study for development strategy}

A pilot approach was made to understand the requirements to develop ergonomic design support as a long term scope of ergonomic investigation in the local small scale industrial units, brass metal work, cane \& bamboo units, fruit processing, handloom sectors were considered. Among the north-eastern states Assam appears to be progressing in industrialisation comprising both traditional as well as modern industries for various consumable produces. It has a few agro-based industries and mineral based industries. Agro-based industries like jute, rice mills, fruit processing, tea industries, etc., are of great economic importance. from local ethnic life style to industrial perspective, various levels of ergonomic hazards reference to these highly labour intensive industries specifically fruit processing and tea industries are silently imposing on large number of women workforces. The work methods in these industries followed are mainly manual labour oriented, as machines are either not convenient or do not go along with the traditional skills practiced so far. Based on the visits to the local production units in Assam; fruit processing unit of Boko, Assam was chosen as base location to get the relevant information and for validation other local units of neighbouring locations, i.e., Shillong and MIDC Industrial Area of Meghalaya were chosen as representatives of small scale production units with export potential; and for corporate sector tea gardens of Jorhat, Assam were considered for detailed study about the occupational status, work methods followed and the work tools are being used in order to find an appropriate to the context design development strategy.

Workers task cycle was observed, their limitations and aspirations were discussed, and the managements' views on the possible development feasibilities were taken into consideration. Few interim design improvements of hand tools have been made and based on trials and discussions, the strategies for such development were confirmed with workers and management combined views. The critical question concerns with the priority to be allocated for work simplification with context specific design intervention and in examining feasibility for making improvement. In this efforts, the present status of local small scale agro-based works transparent the need. Participatory approach brings the people in confidence to choose development measures that is sustainable within their capability and resources limits.

In Assam such approaches in recent years are very few (a new basket suitable for storing and carrying the plucked tea leaves tried out) to report specifically (Fig. 1).

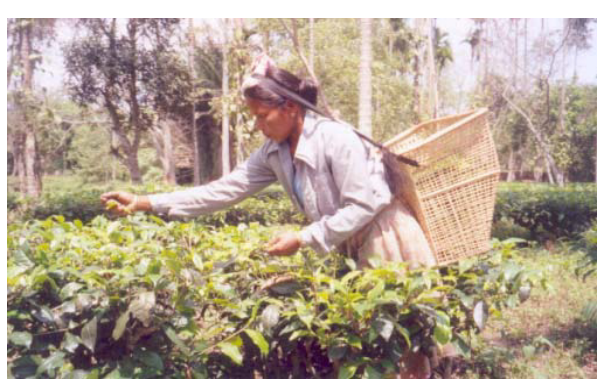

Fig.1: A tea-leaf plucker with the improved basket 


\section{Work status and tool development}

Tea-leaf plucking, and pineapple as a fruit and pickle (from other raw material locally available) processing industries of Assam are highly women labour intensive (Fig. 2, 3). In both the sectors the activities involve numerous combinations of arm and finger movements and their use varies with the skill, experience and degree of fatigue of the workers $[1,4,9]$. To increase the productivity it was essential to look into the need for any work tool development.
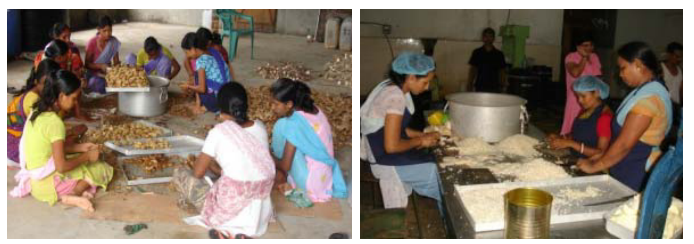

Fig.2: Women workers in pickle making activities

In fruit processing industries in Assam, mostly pineapple is processed in form of canned raw slices and juice, and other seasonal fruits are used mainly for pickle making. Women adopt floor sitting or standing posture and use normal stools as seating device to work on a table surface (Fig. 2, 3). For pineapple, tasks performed by hands only are pealing, eye removing and coring the central hard core (Fig. 4). The pineapple harvest season is short lived and it suffers lose and even production units require to hire unskilled manpower to manage the season to best utilised. Attempts were made to go for mechanical device that can perform the pealing of the skin, de-coring and slice making; but as it suffers a good amount of lose of fruit pulp; no more progress have been done in this. The present authors, as an academic assignment, made an attempt to use mechanisation in pineapple processing and when the idea was presented to the workers and management, they preferred the idea but were not very interested to go for implementing mechanisation and power operated ones. The reasons expressed were: trained manpower is not available to use such machinery and also there is a need for local employment generation. Women are seen to use traditional skill and tools, they select local available material as work tool, and no specialised work tool is supplied by the employer.

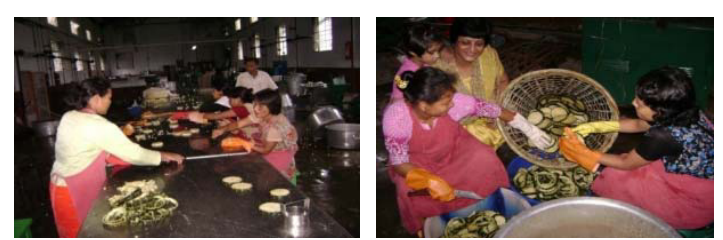

Fig.3: Women workers engaged in pineapple peeling activity
Pineapple processing requires skill and involves a variety of repetitive movements of hands. In the processing unit it was found that women workers were engaged in peeling and coring of pineapple with simple long knives and cylindrical tools respectively (Fig. 4, 5). The process followed sequentially is skin pealing with eyes removal, slicing the flesh with knives and coring the hard central portion from the individual slices.
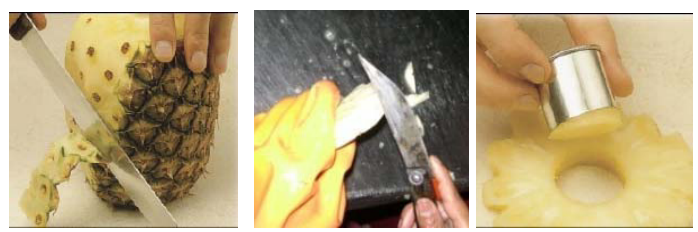

Fig.4: Pineapple peeing and coring

The workers reported to face problems for unavailability of sound peeling and coring tools; and expressed that the work equipment has to be designed to suit to small scale industries limited resources and existing manpower. It was found that during lean period of pineapple women workers are engaged in various tasks of varieties of fruits processing activities. It was opined (when some tips regarding likely to be ways of betterment was discussed) that specific tool development with local materials suitable for specific tasks (as different fruits and vegetable behave differently) and awareness workshops on good work practice would suit better.

The women workers engaged in highly labour intensive sectors perform both single-task job (single task or combinations of task involving repetitive movements for the entire job timing) and multiple-task jobs (job rotations in between) along with their homemaking responsibilities. They are therefore suffering from dual load at home as well as work-related health problems, which are further complicated by social, psychological and women relevant physiological issues. It is noticed, many workers are suffering from some kind of occupation related injuries. It cannot be specifically found in any form of medical record. Shyness, cost of treatment and the fear of losing the job by disclosure of such problems, they refrain these from being formally reported. The existing legislation does not protect the vast majority of the women workers in this sector as well.

The level of risk depends on the duration a worker is exposed to risk factors, the frequency at which they are exposed, and the magnitude of the exposure. Indian studies have shown good progress which is reported in many forum from time to time. In recent years that some workers, trade unions, employers, manufacturers, and researchers have begun to give attention to how workplace/work 
tool/work design can improve the health of worker and ensure safe working aiming at improved productivity. In general it is found that in this agrobased work sector women are more exposed to repetitive and monotonous work and to stressful conditions $[5,10]$, that is still prevailing in case of women workers under the present study coverage.

\section{Ergonomic intervention: work accessories design and methods}

A hand tool becomes "ergonomic" only when it fits the task which is being and intended to be performed, and it fits the hand without causing awkward postures, harmful contact pressures, or other safety and health risks. A tool that does not fit the hand or needs to be used in a way it was not intended (possible misuse), injury or muscle strain may be developed, and repetitive movements that are performed over time or for a long period of time can aggravate the risk.
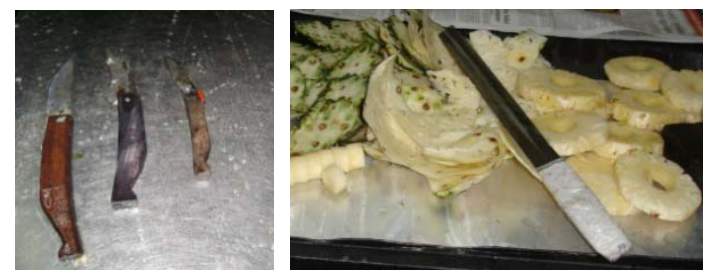

Fig. 5: Existing Pineapple peeling knives

The present study was conducted among women workers engaged in repetitive activities, i.e., tea leaf plucking operation to determine ill physical effects prevalence rate and to assess the level of exposure to risks. Under the study to support the data on consequential effects of repetitive activity, some other industrial activities (with repetitive movement) i.e. peeling of pineapple and pickle making was also studied. Efforts were also made to study the scope for design interventions in both the selected areas. The interaction with the management as well as the workers in tea industries, the organised and corporate sector, revealed that a substantial number of workers are engaged in a single task job for considerable shift duration that is approximately 440 minutes per day. A specific design development for plucking may produce a good result through a corporate decision. Where as in small fruit processing units (mostly private owned) workers are engaged in multi-task jobs depending on availability of materials and skill in an unpredictable supply-demand production scenario, the design development may need context specific approach and the developmental efforts may be participatory. Thus to see the effect of design (work tool) intervention applicable for a large working group with corporate decision for tea-leaf plucking operation was considered for in depth enquiry.

Almost all the fruit processing industries, particularly the small and medium are in the hands of private ownership. They do not have access to latest technology because of the prohibitive cost. Workers, especially the women workers are engaged in multiple-task job. Moreover there is no fixed allotment of job among the workers. The workers perform various activities as and when required. Therefore design intervention is not a single work tool type development oriented. The workers use local utility items available with their own modifications for easy performance. For this purpose trainings on ergonomics principles will be a helpful measure for the workers. So far need based trainings on ergonomics programs have not yet been conducted in these units of Assam.

The present pilot enquiry among various fields of engagement, the tea leaf plucking was identified as a potential area. Here small and low cost tool development can be attempted, rather shear type devices that does not provide appropriate provision for selection of apex tea shoots (two leaves and a bud) and is not comfortable to work with the existing manpower and skill.

An ergonomic plucking aide was conceptualised, designed and developed. It is a finger guard with blade embedded to facilitate plucking and protect finger aberrations. It was tested on the workers of its suitability followed by feedback based modifications through participatory approach engaging the direct beneficiaries to be the part of development process. The design was not only found suitable to improve productivity, its workcomfort value was also welcomed by the workers.

\section{Conclusion}

Ergonomic design intervention would be context specific viewing to improve overall occupational well-being and possibility of work tool design development that can reduce the ergonomic risk factors and improve productivity in the agro-based industry development process in northeast region of India. In small-scale fruit processing centers the productivity is directly related to the harvesting season of the raw materials and throughout the year workers go on shifting to various kinds of fruit processing which require different work tools. Mostly workers manage work tools of their own and the decision of their engagement and use of tools are not centrally conceived by the production units. The development process would be specific to the fruit/ vegetable concern and the techniques should suit to perform the task as desired. In contrast in tea gardens, a tea-leaf plucking device/aid would be preferable as the tea-leaf 
pluckers are engaged in same job throughout the year, and the work schedule and work equipment is decided and supplied to them based on the corporate decision where the workers do not have any individual control. Thus the work tool design development strategies for both the sectors (tea and fruit processing) have to be seen with different perspectives respectively.

\section{References}

[1] D. Chakrabarti, Design Ergonomics: need and role", Udyog Pragati, 25, (2), 2001, 37-44.

[2] K.. Kogi, Ergonomics and Technology transfer into small and medium-sized enterprises, Proceedings of the $13^{\text {th }}$ Triennial conference of the IEA, Tampere, Finland,.7, 1997, 638-640.

[3] L.P. Gite, and. B.G. Yadav, Optimum handle height for a push-pull type manually-operated dry land weeder, Ergonomics 33 (12), 1990, 1487-1494.

[4] N. Bhattacharyya, S.C. Baruah, R. Borah, P.Bhagawati, Ergonomic assessment of postures assumed by workers in tea cultivation, Proceedings of Interantional conference on HWWE'05 held in IIT, Guwahati, 2005.

[5] National Institute for Occupational Safety and Health (NIOSH), Ahmedabad, India, 2010, Report on: Stress at work

[6] P.C. Ghosh, Application of Ergonomics in Indian Industry", Proceedings of HWWE2005, 2005, 65-68.

[7] P.K. Nag and C.K. Pradhan, Ergonomics in the hoeing operation. Int $\mathrm{J}$ Industrial Ergonomics (Special issue : Agricultural Ergonomics, 1992, 10, 341.

[8] R.N. Sen, Application of ergonomics to industrially developing countries, Ergonomics, 27(10), 1984, 10211032.

[9] R.N., Sen, A.K. Ganguli and G.G. Ray, Ergonomics study of tea-leaf plucking operations: Criteria for section and categorization, Applied Ergonomics, 12(2), 1981, 83-85.

[10]Srivastava, A.K. and Bihari, V., Occupational health for women: A current need. J Sci Indian Res. 59, 2000, 9951001 . 